\title{
Design and development of second-generation titanium oxide photocatalysts to better our environment-approaches in realizing the use of visible light
}

\author{
Masakazu Anpo and Masato Takeuchi \\ Department of Applied Chemistry, Graduate School of Engineering Osaka Prefecture University \\ 1-1 Gakuen-cho, Sakai, Osaka 599-8531, Japan
}

\begin{abstract}
The design and development of second-generation titanium oxide photocatalysts which absorb UV-visible light and work as efficient photocatalysts under irradiation of light in the UV-visible light regions were successfuly carried out by applying advanced metal ion-implantation techniques. Titanium oxide catalysts were implanted with various transition-metal ions by a high-voltage acceleration technique, then calcined in $\mathrm{O}_{2}$ at around $723-823 \mathrm{~K}$ to produce photocatalysts capable of absorbing visible light, the extent of such red shift depending on the kind and amount of metal ion implanted. The transition-metal ionimplanted titanium oxide photocatalysts, specifically using $\mathrm{V}, \mathrm{Mn}$, or $\mathrm{Cr}$ ions, were successful in carring out various photocatalytic reactions such as the decomposition of $\mathrm{NO}_{\mathrm{x}}$ and the reaction involving the decomposition of $\mathrm{H}_{2} \mathrm{O}$ at $295 \mathrm{~K}$, significantly under irradiation with visible light longer than $450 \mathrm{~nm}$. In outdoor field reactivity tests, these $\mathrm{V}$ or $\mathrm{Cr}$ ion-implanted titanium oxide photocatalysts showed four to three times higher photocatalytic reactivity for those photocatalytic reactions under solar beam irradiation, as compared with the original unimplanted titanium oxide photocatalyst. The advantages and possibilities of utilizing such second-generation titanium oxide photocatalysts are the only way to address environmental pollution on a large and global scale.
\end{abstract}

\section{INTRODUCTION}

Environmental pollution and destruction on a global scale have drawn attention to the vital need for totally new, safe and clean chemical technologies and processes, the most important challenge facing chemical scientists for the 21 st century. Strong contenders as environmentally harmonious catalysts are titanium oxide photocatalysts which can operate at room temperature in a clean and safe manner while applications of such photocatalytic systems are urgently desired for the purification of polluted water, the decomposition of offensive atmospheric odors as well as toxins, the fixation of $\mathrm{CO}_{2}$ and the decomposition of NOx and chlorofluorocarbons on a global scale [1-8]. Furthermore, transparent titanium oxide thin film photocatalysts prepared on glass, tile and various architectural materials have been actively investigated as promising antibacterial, self-cleaning and deodorization systems [6, 7].

However, unlike photosynthesis in green plants, the titanium oxide photocatalyst in itself does not allow the use of visible light and can make use of only $3-4 \%$ of solar beams that reach the earth. Therefore, to address such enormous tasks, photocatalytic systems which are able to operate effectively and efficiently not only under UV but also under the most environmentally ideal energy source, sunlight, must be established.

\footnotetext{
† E-mail: anpo@ok.chem.osakafu-u.ac.jp
}

To this end, it is vital to design and develop unique titanium oxide photocatalysts which can absorb and operate with high efficiency under solar and/or visible light irradiation [9-16].

This chapter deals with the design and development of such unique second-generation titanium oxide photocatalysts which absorb UV-visible light and operate effectively under visible and/or solar beam irradiation by applying an advanced metal ion-implantation method.

\section{EXPERIMENTAL SECTION}

The main characteristics of the various titanium oxide catalysts used in this chapter have been summarized in Table 1. Titanium oxide thin film photocatalysts were prepared using an ionized cluster beam (ICB) method [13-16]. Using ICB, the titanium metal was heated to $2200 \mathrm{~K}$ in a crucible and Ti vapor was introduced into the high vacuum chamber to produce Ti clusters. These clusters then reacted with $\mathrm{O}_{2}$ in the chamber and stoichiometric titanium oxide clusters were formed. The ionized titanium oxide clusters formed by electron beam irradiation were accelerated by a high electric field and bombarded onto the glass substrate to form titanium oxide thin films.

The metal ion-implantation of the catalysts was carried out using an ion-implanter consisting of a metal ion source, mass analyzer, high voltage ion accelera- 
Table 1. Characteristics of the titanium oxides used in the present study.

\begin{tabular}{lcllll}
\hline Catalyst & $\begin{array}{c}\text { Anatase, } \\
\%\end{array}$ & $\begin{array}{l}\text { BET surface } \\
\text { area, m2/g }\end{array}$ & $\begin{array}{l}\text { Particle } \\
\text { size, nm }\end{array}$ & $\begin{array}{l}\text { Purity as } \\
\text { TiO2, \% }\end{array}$ & $\begin{array}{l}\text { Bandgap } \\
\text { energy, eV }\end{array}$ \\
\hline F-2 & 72.3 & 27.1 & 23.4 & 99.97 & 3.25 \\
F-4 & 87.5 & 54.2 & 15.0 & 99.97 & 3.251 \\
F-6 & 81.0 & 102 & 9.30 & 99.99 & 3.262 \\
P-25 & 70.9 & 50.2 & 18.6 & 99.54 & 3.250 \\
S-1 & 86.1 & 30.6 & 30.2 & 99.90 & 3.252 \\
\hline
\end{tabular}
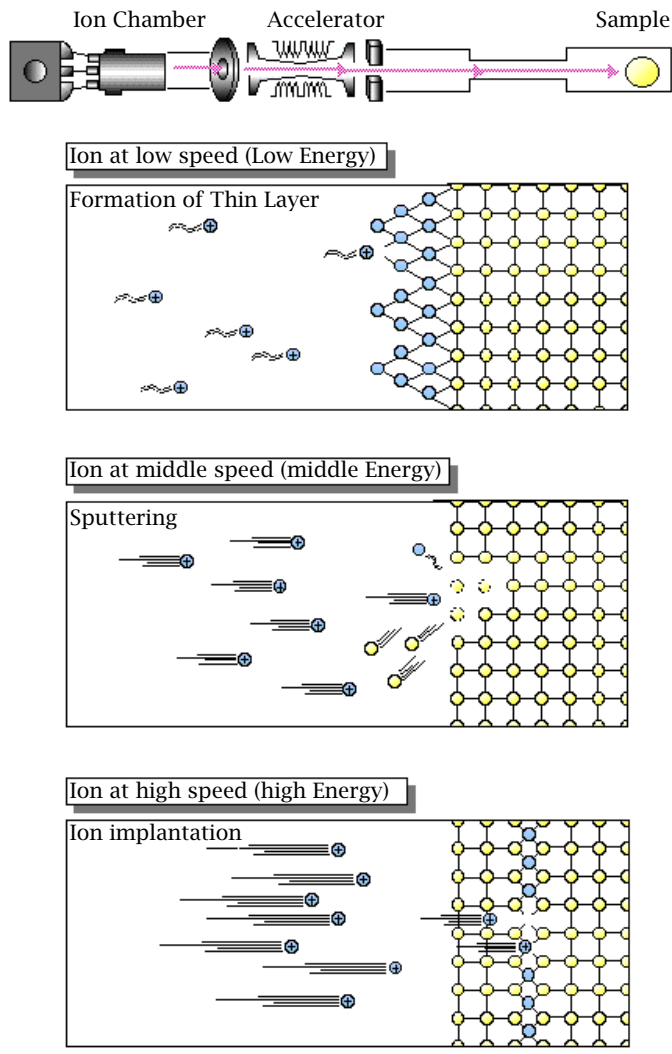

Figure 1. Schematic diagram of an advanced metal ionimplantation method. High energy implantation (bottom) was used in the present studies.

tor (50-200 keV), and a high vacuum pump (Figure 1) [2-5, 10-12]. The metal ions were expected to be injected into the deep bulk of the catalyst when high acceleration energy was applied to the metal ions. In fact, as expected, SIMS analyses using a Shimadzu/Kratos SIMS1030 clearly showed that the metal ions implanted into the titanium oxide catalyst exist in a highly dispersed state and are injected into the deep bulk of the catalyst, exhibiting a distribution maximum at around $1000-3000 \AA$ from the surface and zero distribution at the surface [10-12]. Although such distribution depends on the acceleration energy and the kind of catalyst, one of the most significant advantages in using the metal ion implantation method is to modify the bulk electronic properties of a catalyst.

The metal ion-implanted titanium oxide catalysts were calcined in $\mathrm{O}_{2}$ at around $723-823 \mathrm{~K}$ for $5 \mathrm{~h}$. Prior to various spectroscopic measurements such as UV-VIS diffuse reflectance, SIMS, XRD, EXAFS, ESR and ESCA as well as invesigations on the photocatalytic reactions, both the metal ion-implanted and unimplanted original pure titanium oxide photocatalysts were heated in $\mathrm{O}_{2}$ at $753 \mathrm{~K}$ and then degassed in cells at $753 \mathrm{~K}$ for $2 \mathrm{~h}$, heated in $\mathrm{O}_{2}$ at the same temperature for $2 \mathrm{~h}$, and finally outgassed at $473 \mathrm{~K}$ to $10^{-6}$ Torr [12-15].

Light irradiation of the photocatalysts in the presence of reactant molecules such as NOx and a mixture of $\mathrm{CH}_{3} \mathrm{C} \equiv \mathrm{CH}$ and $\mathrm{H}_{2} \mathrm{O}$ was carried out using a highpressure Hg lamp (Toshiba SHL-100UV) through water and color filters, i.e., $\lambda>450 \mathrm{~nm}$ for visible light irradiation and $\lambda<380 \mathrm{~nm}$ for UV irradiation, respectively, at $275-295 \mathrm{~K}$. The reaction products were analyzed by GC and GC-MASS. The UV-VIS diffuse reflectance spectra were measured using a Shimadzu UV-2200A spectrophotometer at $295 \mathrm{~K}$. The ESR spectra were recorded at $77 \mathrm{~K}$ with a Bruker ESP300E and a JEOL RE-2X spectrometer (X-band). The binding energies and the element composition of the catalysts were measured using a Shimadzu ECSA-3200 electron spectrometer. The XAFS (XANES and FT-EXAFS) spectra were measured at the BL-7C facility of the Photon Factory at the National Laboratory for High-Energy Physics, Tsukuba.

\section{RESULTS AND DISCUSSION}

The metal ion-implantation method was applied to modify the electronic properties of titanium oxide photocatalysts by bombarding them with high energy metal ions, and it was discovered that metal ion-implantation with various transition metal ions such as $\mathrm{V}, \mathrm{Cr}, \mathrm{Mn}$, Fe and Ni accelerated by high voltage enables a large shift in the absorption band of the titanium oxide catalysts toward visible light regions, with differing levels of effectiveness. However, $\mathrm{Ar}, \mathrm{Mg}$, or Ti ion-implanted titanium oxides exhibited no shift, showing that such a shift is not caused by the high energy implantation process itself, but to the interaction of the transition metal ions with the titanium oxide catalyst. As can be seen in Figure 2-(b-d), the absorption band of the $\mathrm{Cr}$ 


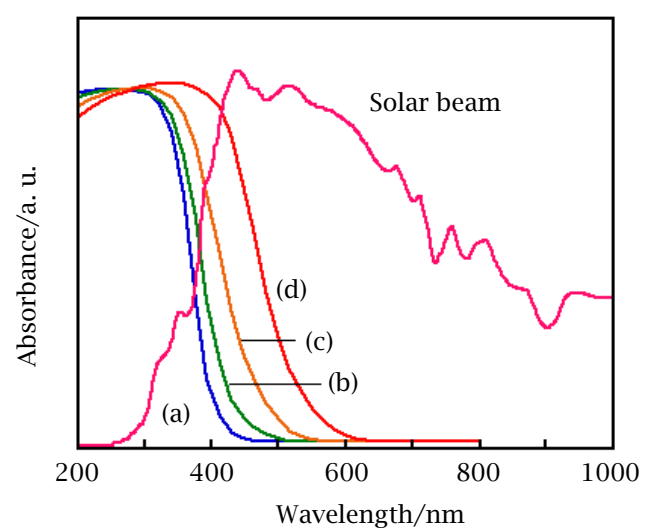

Figure 2. Uv-Vis absorption spectra (diffuse reflectance) of the original unimplanted pure $\mathrm{TiO}_{2}$ (a) and the $\mathrm{Cr}$ ionimplanted $\mathrm{TiO}_{2}(b-d)$, and the solar spectrum which reaches the earth. (amounts of $\mathrm{Cr}$ ion-implanted in $10^{-7} \mathrm{~mol} / \mathrm{g}, \mathrm{b}$ : 2.2, c: 6.6, d: 13.0)

ion-implanted titanium oxide shifts smoothly to visible light regions, the extent of the red shift depending on the amount and type of metal ions implanted, with the absorption maximum and minimum values always remaining constant. The order of the effectiveness in the red shift was found to be $\mathrm{V}>\mathrm{Cr}>\mathrm{Mn}>\mathrm{Fe}>\mathrm{Ni}$ ions. Such a shift allows the metal ion-implanted titanium oxide to use solar beams more effectively and efficiently, at up to $20-30 \%[4,12]$.

Furthermore, as shown in Figure 3, such red shifts in the absorption band of the metal ion-implanted titanium oxide photocatalysts can be observed for any kind of titanium oxide except amorphous types, the extent of the shift changing from sample to sample.

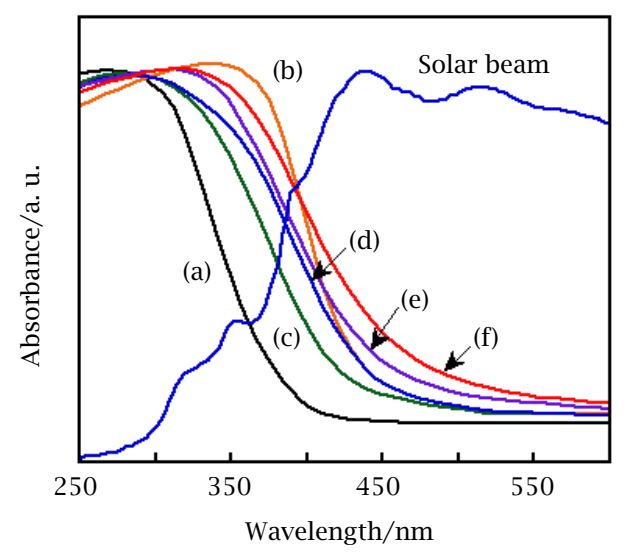

Figure 3. Shifts in the absorption spectra of various types of $\mathrm{TiO}_{2}$ photocatalysts (shown in Table 1) implanted with the same amounts of $\mathrm{V}$ ions. a: original unimplanted pure p-25, b: V/F-6, c: V/F-4, d: V/P-25, e: V/F-2, f: F/S-1. (amount of $\mathrm{V}$ ion-implanted was $6.6 \times 10^{-7} \mathrm{~mol} / \mathrm{g}\left(3.4 \times 10^{-3} \mathrm{wt} \%\right)$
It was also found that such shifts in the absorption band can be observed only after calcination of the metal ion-implanted titanium oxide samples in $\mathrm{O}_{2}$ at around $723-823 \mathrm{~K}$. Therefore, calcination in $\mathrm{O}_{2}$ in combination with metal ion-implantation was found to be instrumental in the shift of the absorption spectrum toward visible light regions. These results clearly show that shifts in the absorption band of the titanium oxides by metal ion-implantation are a general phenomenon and not a special feature of a certain kind of titanium oxide catalyst.

Figure 4 shows the absoprtion bands of the titanium oxide photocatalysts impregnated or chemically doped with $\mathrm{Cr}$ ions in large amounts as compared with those for $\mathrm{Cr}$ ion-implanted samples. The $\mathrm{Cr}$ ion-doped catalysts show no shift in the absorption band, however, a new absorption shoulder appears at around $420 \mathrm{~nm}$ due to the formation of the impurity energy level within the bandgap, its intensity increasing with the amount of $\mathrm{Cr}$ ions chemically doped. Such results indicate that the method of doping causes the electronic properties of the titanium oxides to be modified in completely different ways, thus confirming that only metal ionimplanted titanium oxide catalysts show shifts in the absorption band toward visible light regions.

With unimplanted or chemically doped titanium oxide photocatalysts, the photocatalytic reaction does not proceed under visible light irradiation $(\lambda>450 \mathrm{~nm})$. However, we have found that visible light irradiation of metal ion-implanted titanium oxide photocatalysts can initiate various significant photocatalytic reactions. As shown in Figure 5, visible light irradiation $(\lambda>450 \mathrm{~nm})$ of the $\mathrm{Cr}$ ion-implanted titanium oxide in the presence

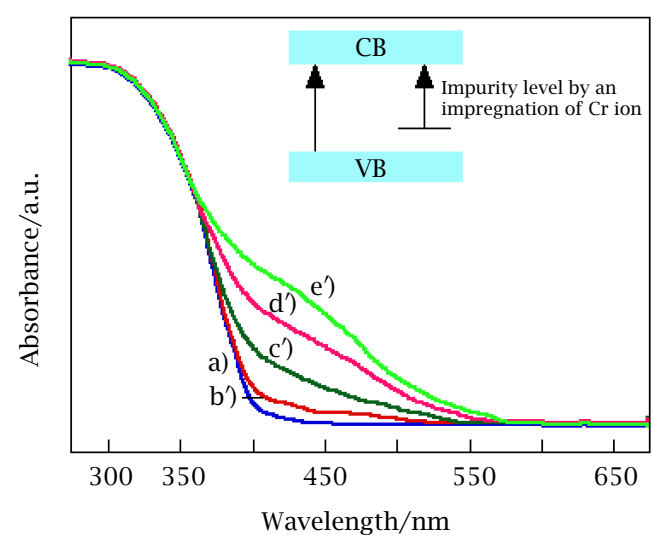

Figure 4. Uv-Vis absorption spectra of (diffuse reflectance) of the original undoped pure $\mathrm{TiO}_{2}$ (a) and $\mathrm{TiO}_{2}$ chemically doped with $\mathrm{Cr}$ ions ( $\left.b^{\prime}-e^{\prime}\right)$. ( $\mathrm{Cr}$ ions chemically doped in $10^{-7} \mathrm{~mol} / \mathrm{g}$, a: undoped original pure $\mathrm{TiO}_{2}(P-25), b^{\prime}: 16$, c': 200, d': 1000, e': 2000) These $\mathrm{TiO}_{2}$ photocatalysts chemically doped with $\mathrm{Cr}$ ions did not exhibit any photocatalytic reactivity. 


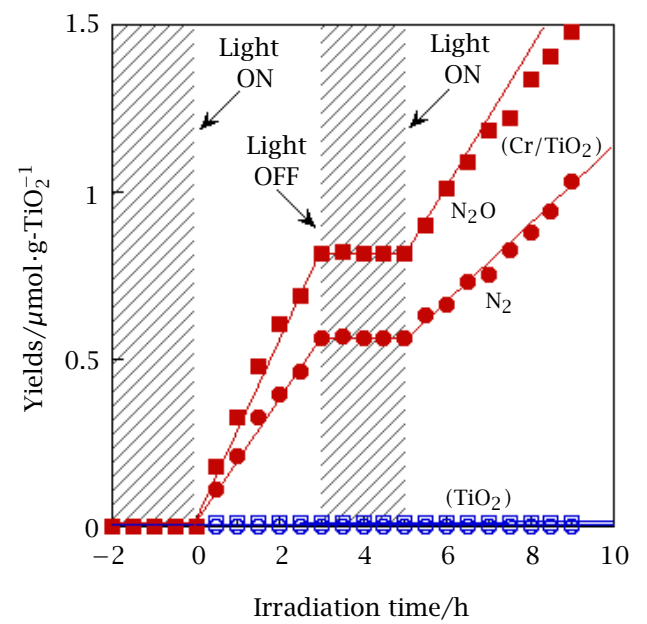

Figure 5. Reaction time profiles of the photocatalytic decomposition of $\mathrm{NO}$ on the $\mathrm{Cr}$ ion-implanted $\mathrm{TiO}_{2}$ photocatalyst under visible light $(\lambda>450 \mathrm{~nm})$ irradiation at $295 \mathrm{~K}$. Unimplanted original pure $\mathrm{TiO}_{2}$ photocatalyst did not show any photocatalytic reactivity under the same reaction conditions.

of $\mathrm{NO}$ at $275 \mathrm{~K}$ leads to the decomposition of NO into $\mathrm{N}_{2}, \mathrm{O}_{2}$, and $\mathrm{N}_{2} \mathrm{O}$ with a good linearity against the irradiation time. Under the same conditions of visible light irradiation, the unimplanted original pure titanium oxide photocatalyst did not exhibit any photocatalytic reactivity. The action spectrum for the reaction on the metal ion-implanted titanium oxide was in good agreement with the absorption spectrum of the photocatalyst shown in Figure 2, indicating that only metal ion-implanted titanium oxide photocatalysts were effective for the photocatalytic decomposition reaction of NO. Thus, metal ion-implanted titanium oxide photocatalysts were found to enable the absorption of visible light up to a wavelength of 400-600 nm and were also able to operate effectively as photocatalysts, hence their name, "second-generation titanium oxide photocatalysts" [4, 11, 15].

It is important to emphasize that the photocatalytic reactivity of the metal ion-implanted titanium oxides under UV light $(\lambda<380 \mathrm{~nm})$ retained the same photocatalytic efficiency as the unimplanted original pure titanium oxides under the same UV light irradiation conditions. When metal ions were chemically doped into the titanium oxide photocatalyst, the photocatalytic efficiency decreased dramatically under UV irradiation due to the effective recombination of the photo-formed electrons and holes through the impurity energy levels formed by the doped metal ions within the bandgap of the photocatalyst (in the case of Figure 4) [17]. These results clearly suggest that metal ions physically implanted do not work as electron and hole recombination centers but only work to modify the electronic property

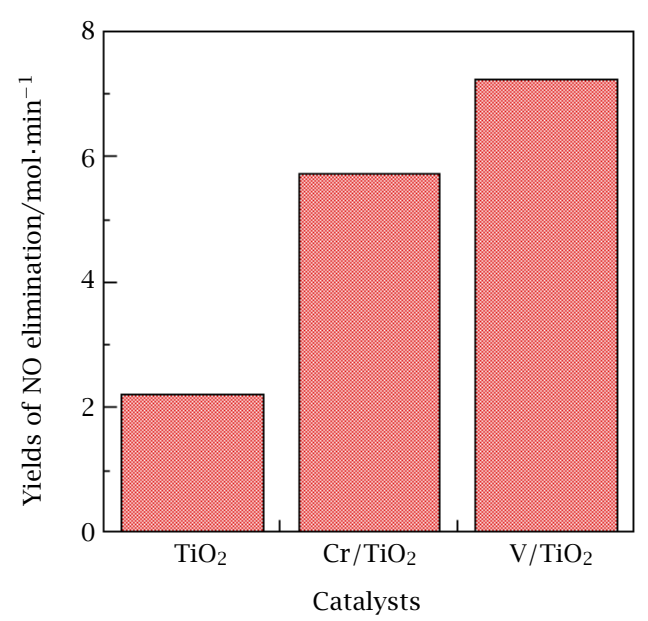

Figure 6. Effect of the $\mathrm{Cr}$ and $\mathrm{V}$ ion-implantation on the photocatalytic reactivity of $\mathrm{TiO}_{2}$ under outdoor solar beam irradiation for the photocatalytic decompositon of NO at $295 \mathrm{~K}$. (solar beam: $38.5 \mathrm{~mW} / \mathrm{cm}^{2}$ )

of the catalyst $[11,12,14,15]$.

We have conducted various field work experiments to test the photocatalytic reactivity of the newly developed titanium oxide photocatalysts under solar beam irradiation. As can be seen in Figure 6, under outdoor solar light irradiation at ordinary temperatures, the $\mathrm{Cr}$ and $\mathrm{V}$ ion-implanted titanium oxide photocatalysts showed several times higher photocatalytic reactivity for the photocatalytic decomposition of NO. As Figure 7 shows, it is also found that under solar light irradiation at ordinary temperatures, the $\mathrm{V}$ ion-implanted titanium oxide photocatalysts showed several times higher photocatalytic reactivity for the photocatalytic hydrogenation of $\mathrm{CH}_{3} \mathrm{C} \equiv \mathrm{CH}$ with $\mathrm{H}_{2} \mathrm{O}$ than the unimplanted original pure titanium oxide photocatalysts. These results, together with the results shown in Figure 2, clearly show that by using second-generation titanium oxide photocatalysts developed by applying the metal ionimplantation method, we are able to utilize visible and solar light energy more efficiently.

The relationship between the depth profiles of the metal ions of the metal ion-implanted titanium oxide photocatalysts having the same number of metal ions, such as $\mathrm{V}$ or $\mathrm{Cr}$ ions, and their photocatalytic efficiency under visible light irradiation were investigated. It was found that when the metal ions were implanted in the same amounts into the deep bulk of the catalyst by applying high voltage acceleration energy, the photocatalyst exhibited a high photocatalytic efficiency under visible light irradiation. On the other hand, when a low voltage was applied, the photocatalyst exhibited a low efficiency under the same conditions of visible light irradiation $[15,16]$.

It was also found that increasing the number (or 


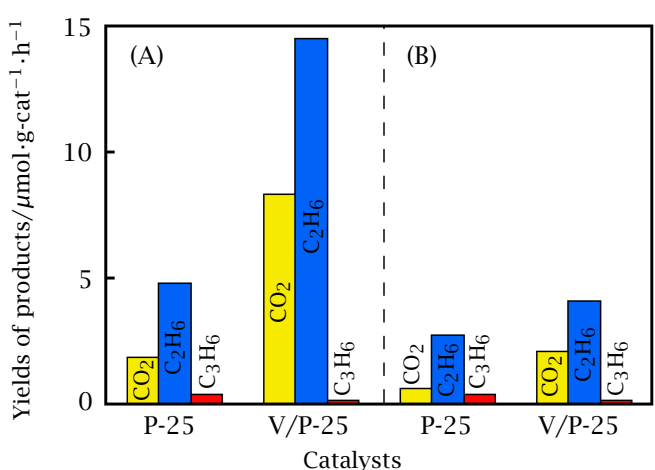

Figure 7. Effect of the $\mathrm{Cr}$ and $\mathrm{V}$ ion-implantation on the photocatalytic reactivity of TiO2 under outdoor solar beam irradiation for the photo-catalytic reaction of $\mathrm{CH}_{3} \mathrm{CCH}$ with $\mathrm{H}_{2} \mathrm{O}$ leading a hydogenolysis reaction of $\mathrm{CH}_{3} \mathrm{CCH}$ with $\mathrm{H}_{2} \mathrm{O}$ at 295 K. (A: fine, B: clody weather) (solar beams of fine weather: $12 \mathrm{~mW} / \mathrm{cm}^{2}$, amount of photocatalyst: $6.0 \mathrm{~g}$ )

amounts) of metal ion-implanted into the deep bulk of the titanium oxides caused the photocatalytic efficiency of these photocatalysts to increase under visible light irradiation, passing through a maximum at around $6 \times 10^{16} \mathrm{~V} / \mathrm{cm}^{2}$ of the catalyst, then decreasing with a further increase in the number of metal ions implanted. Only on samples implanted with an increased number of metal ions could the presence of ions at the near surfaces be observed by ESCA measurements. Thus, these results clearly suggest that there are optimal conditions in the depth and number of metal ions implanted to achieve a high photocatalytic reactivity under visible light irradiation.

The ESR spectra of the $\mathrm{V}$ ion-implanted titanium oxide catalysts were measured before and after calcination of the samples in $\mathrm{O}_{2}$ at around $723-823 \mathrm{~K}$, respectively. Distinct and characteristic reticular $\mathrm{V}^{4+}$ ions were detected only after calcination at around 723$823 \mathrm{~K}$. It was found that when a shift in the absorption band toward visible light regions was observed, the reticular $\mathrm{V}^{4+}$ ions could be detected by ESR. No such reticular $\mathrm{V}$ ions or shift in the absorption band have ever been observed with titanium oxides chemically doped with V ions [16, 18, 19].

Figure 8 shows the XANES and FT-EXAFS spectra of the titanium oxide catalysts physically implanted with $\mathrm{Cr}$ ions (b and B) and also chemically doped with $\mathrm{Cr}$ ions (a and A), respectively. Analyses of these XANES and FT-EXAFS spectra show that in the titanium oxide catalysts chemically doped with $\mathrm{Cr}$ ions by an impregnation or sol-gel method, the ions are present as aggregated $\mathrm{Cr}$-oxides having octahedral coordination similar to $\mathrm{Cr}_{2} \mathrm{O}_{3}$ and tetrahedral coordination similar to $\mathrm{CrO}_{3}$, respectively. On the other hand, in the catalysts physically implanted with $\mathrm{Cr}$ ions, the ions are present in a highly dispersed and isolated state in octahedral coor-
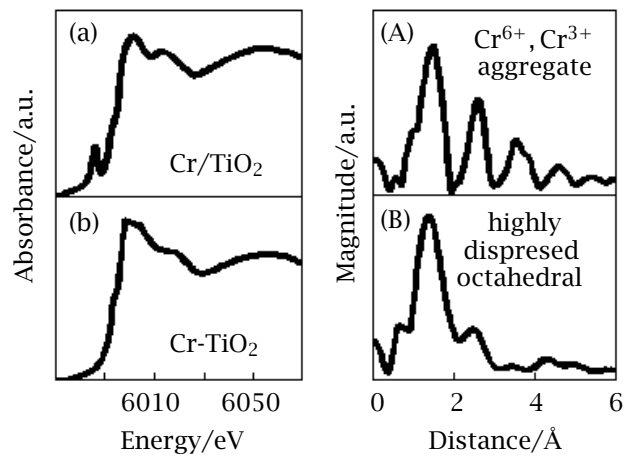

Figure 8. XANES (left) and FT-EXAFS spectra (right) of $\mathrm{Cr}$ ion chemically doped $\mathrm{TiO}_{2}(a)$ and $(A)$ and $\mathrm{Cr}$ ion-implanted $\mathrm{TiO}_{2}$ catalysts (b), (B), respectively.<smiles>O[Te+3](O)(O)(O)O[Te](O)(O)(O)(O)O</smiles>

Scheme 1. Molecular structure of titanium oxide photocatalyst modified by metal ion-implantation. Metal ions are located at the latice position in substitution of $\mathrm{Ti}^{4+}$.

dination, clearly suggesting that the $\mathrm{Cr}$ ions are incorporated in the lattice positions of the catalyst in place of the Ti ions.

Our results clearly show that modification of the electronic state of titanium oxide by metal ionimplantation is closely associated with the strong and long distance interaction which arises between the titanium oxide and the metal ions implanted, as shown in Scheme 1 , and not by the formation of impurity energy levels within the bandgap of the titanium oxides resulting from the formation of impurity oxide clusters which are often observed in the chemical doping of metal ions, as shown in Figures 4 and Scheme 2.

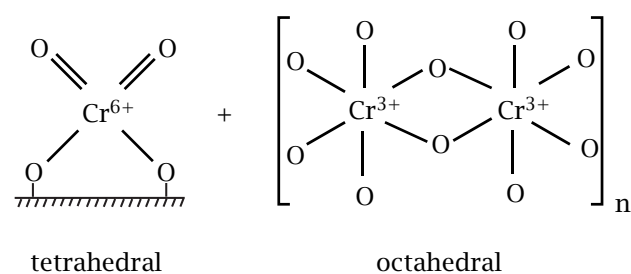

Scheme 2. Molecular structure of titanium oxide photocatalyst chemically doped with $\mathrm{Cr}$ ions. Clusters of $\mathrm{Cr}$ oxides are formed in $\mathrm{TiO}_{2}$. 


\section{CONCLUSIONS}

The advanced metal ion-implantation method has been successfully applied to modify the electronic properties of the titanium oxide photocatalysts, enabling the absorption of visible light even longer than $550 \mathrm{~nm}$ and initiating the photocatalytic reactions effectively not only under UV but also visible light irradiation. The results obtained in the photocatalytic reactions and various spectroscopic measurements of the photocatalysts indicate that the implanted metal ions are highly dispersed within the deep bulk of the catalysts and work to modify the electronic nature of the photocatalysts without any changes in the chemical properties of the surfaces. These modifications were found to be closely associated with an improvement in the reactivity and sensitivity of the photocatalyst, thus enabling the titanium oxides to absorb and operate effectively not only under UV but also under visible light irradiation. As a result, under outdoor solar light irradiation at ordinary temperatures, metal ion-implanted titanium oxide photocatalysts showed several times higher photocatalytic efficiency than the unimplanted original pure titanium oxide photocatalyst.

Thus, the advanced metal ion-implantation method has opened the way to many innovative possibilities, and the design and development of such unique titanium oxide photocatalysts can also be considered an important breakthrough in the utilization of solar light energy which will advance research in sustainable green chemistry for a better environment $[4,5,15,16,20]$.

\section{ACKNOWLEDGMENTS}

The author is greatly indebted to the Petroleum Energy (PEC) supported by the New Energy and Industrial Technology Development (NEDO) as well as The Ministry of International Trade and Industry (MITI) and the 1998 Mitsubishi Foundation for their financial support.

\section{References}

[1] Photocatalysis, N. Serpone and E. Pelizzetti (eds.), John Wiley \& Sons, New York, 1989.
[2] M. Anpo, Catal. Surveys Jpn. 2 (1997), 167.

[3] M. Anpo, Proc. 1st Int. Conf. Protect. the Environ., Rome (1998), 75.

[4] M. Anpo, Green Chemistry, P. Tundo and P. Anastas (eds.), Oxford University Press, 2000, P. 1.

[5] M. Anpo, Pure Appl. Chem. 72 (2000), 1787.

[6] M. Takeuchi, H. Yamashita, M. Matsuoka, and M. Anpo, Catal. Lett. 67 (2000), 135.

[7] N. Negishi, T. Iyoda, K. Hashimoto, and A. Fujishima, Chem. Lett. (1995), 841.

[8] K. Takami, N. Sagawa, H. Uehara, and M. Anpo, Shokubai 41 (1999), 295.

[9] H. Yamashita, M. Honda, M. Harada, Y. Ichihashi, and M. Anpo, J. Phys. Chem. B 102 (1998), 10707.

[10] M. Anpo and M. Takeuchi, Handbook of Ion Engineering, 2001, (in press).

[11] M. Anpo, H. Yamashita, and Y. Ichihashi, Optronics 186 (1997), 161.

[12] M. Anpo, Y. Ichihashi, M. Takeuchi, and $H$. Yamashita, Res. Chem. Intermed. 24, (1998) 143.

[13] M. Anpo, Y. Ichihashi, M. Takeuchi, and H. Yamashita, Stud. Surf. Sci. Catal. H. Hattori and K. Otsuka (eds.), 121, Kodansha-Elsevier, 1999, P. 305.

[14] M. Anpo, M. Takeuchi, S. Kishiguchi, and H. Yamshita, Surf. Sci. Jpn. 20 (1999), 60.

[15] M. Anpo et al., US patent No. 6,077,492 (June 20, 2000).

[16] M. Anpo, Stud. Surf. Sci. Catal. 130 A, 12th Intern. Congr. Catal. A. Corma, F. V. Melo, S. Mendioroz, J. L. and G. Fierro (eds.), part A, Elsevier Science V. B., 2000, P. 157.

[17] H. Paul Maruska and A. K. Ghosh, Solar Energy Mater. 1 (1979), 237.

[18] B. Morin, A. Davidson, M. Che, Y. Ichihashi, and M. Anpo, Unpublished data.

[19] M. Anpo, S. Kishiguchi, K. Ikeue, M. Takeuchi, H. Yamashita, B. Morin, A. Davidson, and M. Che, Res. Chem. Intermed. 27 (2001), (in press).

[20] M. Anpo, Photocatalysis-Foundamental and Applications, M. Kaneko and I. Okura (eds.), Kodanshya, 2001, (in press). 


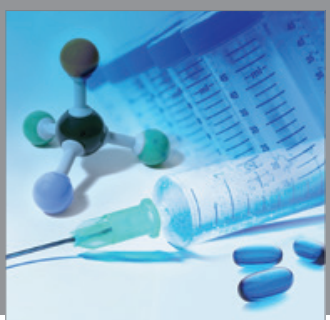

International Journal of

Medicinal Chemistry

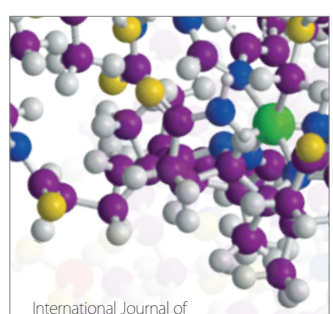

Carbohydrate Chemistry

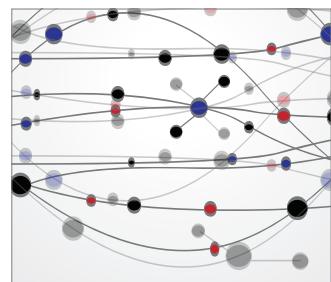

The Scientific World Journal
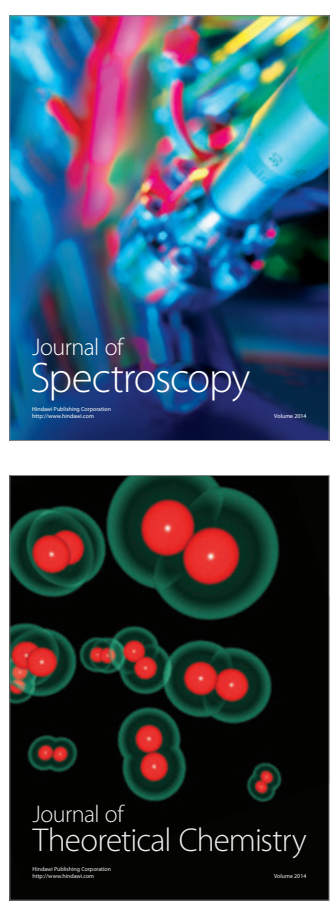
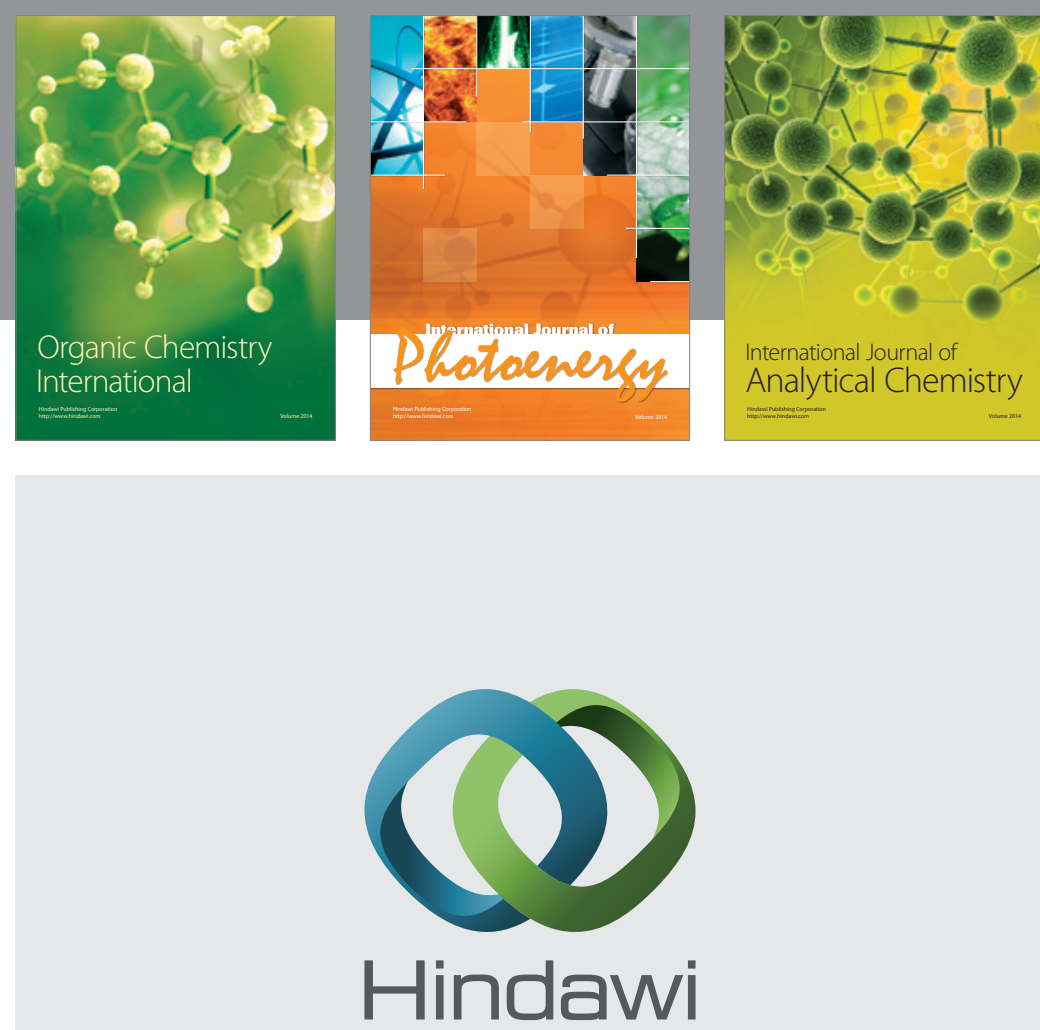

Submit your manuscripts at

http://www.hindawi.com
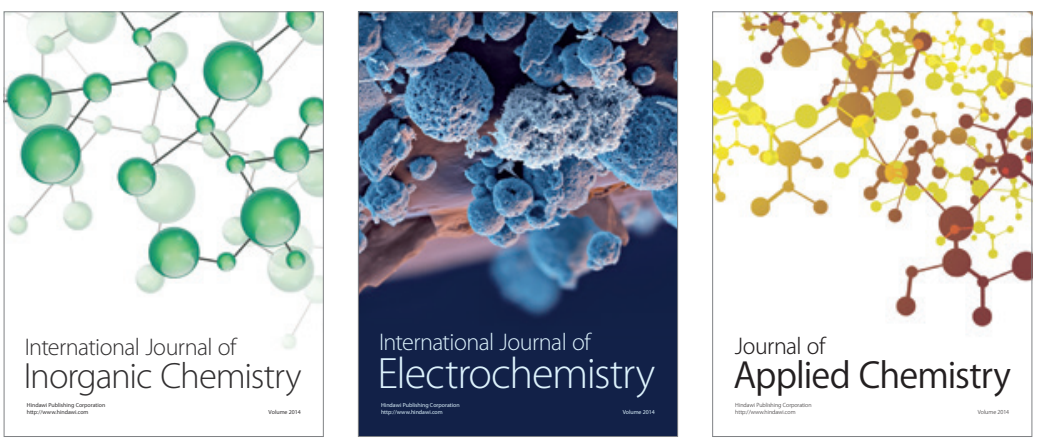

Journal of

Applied Chemistry
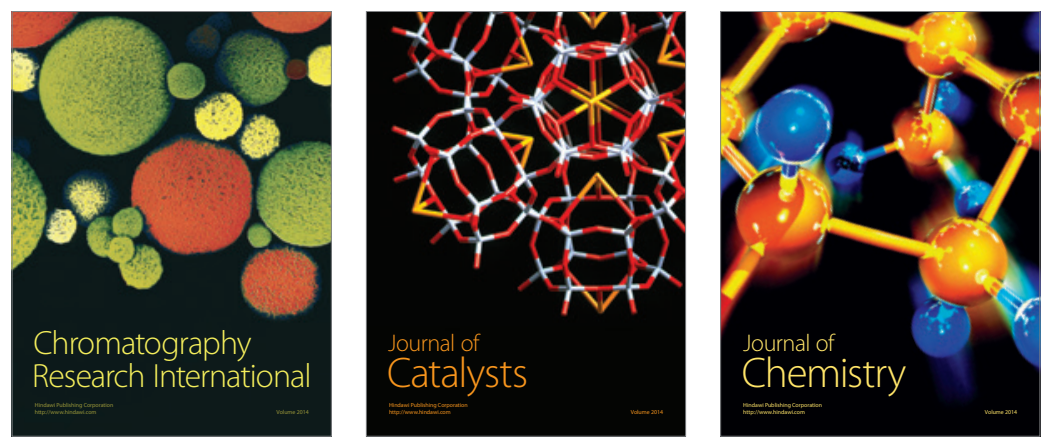
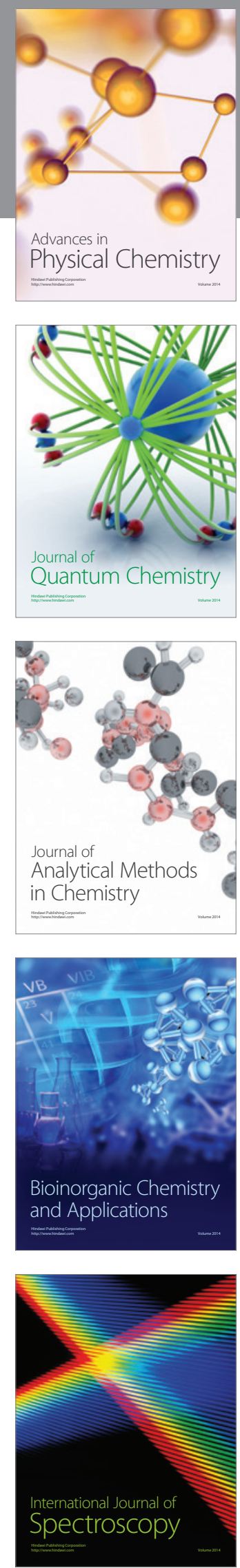